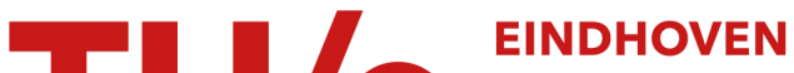 UNIVERSITY OF TECHNOLOGY
}

\section{On characterization of the core of lane covering games via dual solutions}

\section{Citation for published version (APA):}

Hezarkhani, B., Slikker, M., \& Woensel, van, T. (2013). On characterization of the core of lane covering games via dual solutions. (BETA publicatie : working papers; Vol. 439). Technische Universiteit Eindhoven.

\section{Document status and date:}

Published: 01/01/2013

\section{Document Version:}

Publisher's PDF, also known as Version of Record (includes final page, issue and volume numbers)

\section{Please check the document version of this publication:}

- A submitted manuscript is the version of the article upon submission and before peer-review. There can be important differences between the submitted version and the official published version of record. People interested in the research are advised to contact the author for the final version of the publication, or visit the $\mathrm{DOI}$ to the publisher's website.

- The final author version and the galley proof are versions of the publication after peer review.

- The final published version features the final layout of the paper including the volume, issue and page numbers.

Link to publication

\section{General rights}

Copyright and moral rights for the publications made accessible in the public portal are retained by the authors and/or other copyright owners and it is a condition of accessing publications that users recognise and abide by the legal requirements associated with these rights.

- Users may download and print one copy of any publication from the public portal for the purpose of private study or research.

- You may not further distribute the material or use it for any profit-making activity or commercial gain

- You may freely distribute the URL identifying the publication in the public portal.

If the publication is distributed under the terms of Article $25 \mathrm{fa}$ of the Dutch Copyright Act, indicated by the "Taverne" license above, please follow below link for the End User Agreement:

www.tue.nl/taverne

\section{Take down policy}

If you believe that this document breaches copyright please contact us at:

openaccess@tue.nl

providing details and we will investigate your claim. 


\section{Beta}

Research School for Operations

Management and Logistics

\section{On Characterization of the Core of Lane Covering} Games via Dual Solutions

Behzad Hezarkhani, Marco Slikker, Tom van Woensel

Beta Working Paper series 439

\begin{tabular}{|rl|}
\hline BETA publicatie & WP 439 (working \\
& paper) \\
ISBN & \\
ISSN & \\
NUR & \\
Eindhoven & November 2013 \\
\hline
\end{tabular}




\title{
On Characterization of the Core of Lane Covering Games via Dual Solutions
}

\author{
Behzad Hezarkhani, Marco Slikker, Tom van Woensel \\ OPAC, School of Industrial Engineering, \\ Eindhoven University of Technology, The Netherlands
}

November 28, 2013

\begin{abstract}
The lane covering game (LCG) is a cooperative game where players cooperate to reduce the cost of cycles that cover their required lanes on a network. We discuss the possibilities/impossibilities of a complete characterization of the core via dual solutions in LCGs played among a collection of shippers, each with a number of service requirements along some lanes, and show that such a complete characterization is possible if each shipper has at most one service requirement.
\end{abstract}

\section{Introduction}

In any cooperative situation, the division of joint costs is a critical issue. The core of a cooperative game contains allocations that provide players with sufficient incentives to remain in the grand coalition. In general, finding an allocation in the core as well as testing the core-membership of a given allocation are computationally difficult problems as they involve dealing with a number of inequalities which grow exponentially in the number of players. In linear production games (Owen, 1975), every solution to the corresponding dual linear program yields an allocation in the core thus core allocations can be found in polynomial time (Schrijver, 1998). Although testing the membership of a given allocation to the core for this class of games is generally co-NP-complete (Fang et al., 2002), in some cases, e.g. flow games on simple networks (Kalai and Zemel, 1982), dual solutions obtain all allocations in the core. This note addresses the possibilities/impossibilities of a complete characterization of the core via dual solutions in lane covering games.

The lane covering game (LCG), introduced by Özener and Ergun (2008), can be represented as an instance of linear production games where players cooperate to reduce the cost of cycles that cover their required lanes. Özener and Ergun (2008) show that if each required lane is considered to be a single player, the dual solutions completely characterize the core of corresponding game. We extend and complete this result by allowing shippers to be the actual players. Each shipper might have several service requirements (across one or multiple 
lanes). We specify the situations in which the core can or cannot be completely characterized by dual solutions. The main contribution of this note is to prove that a complete characterization of the core via duals is possible if every shipper has at most one service requirement. We also provide examples of LCGs where such a complete characterization fails.

\section{Lane Covering Games (LCG)}

Consider a collection of locations and the network of roads in between. There are several shippers who provide truckload deliveries between pairs of locations. After fulfilling its planned deliveries, every shipper must return to its starting location (repositioning). By collaboration, shippers can reduce the total repositioning cost needed for fulfilling their consolidated deliveries.

Consider the complete directed graph $G=(N, A)$ where $N$ is a finite set of nodes and $A=\{i j \mid i, j \in N, i \neq j\}$ is the set of ordered lanes. The service cost vector $c=\left(c_{i j}\right)_{i j \in A}$ gives the non-negative costs of servicing the lanes. Traversing lane $i j$ without providing service would cost $\theta c_{i j}$ with $0 \leq \theta \leq 1$. A finite set of shippers (players) $P$ operate on $G$. A given player $k \in P$ has an individual requirement vector $r^{k}=\left(r_{i j}^{k}\right)_{i j \in A}$ where $r_{i j}^{k} \in \mathbb{N} \cup\{0\}$ is the number of service requirements of $k$ along the lane $i j$. A player $k$ is called a simple shipper if $\sum_{i j \in A} r_{i j}^{k}=1$. That is, a simple shipper has a single service requirement. We define a lane covering situation as the tuple $\Gamma=\left(G, c, \theta, P,\left(r^{k}\right)_{k \in P}\right)$.

A cooperative cost game is a pair $(P, z)$ with the set of players $P$ and $z: 2^{P} \rightarrow \mathbb{R}$ being the characteristic function that assigns to every coalition $S \subseteq P$ the cost $z(S)$. The lane covering game (LCG) associated with situation $\Gamma$ is a cooperative cost game $\left(P, z^{\Gamma}\right)$ where $z^{\Gamma}(S)$ is the minimum cost of covering the service requirements of $S \subseteq P$, i.e. $r^{S}=\sum_{k \in S} r^{k}$, via cycles. For any $S \subseteq P, z^{\Gamma}(S)$ can be obtained by the following integer linear program:

$$
\begin{aligned}
& \text { Model 1: } \quad z^{\Gamma}(S)=\min \sum_{i j \in A} c_{i j} x_{i j}+\theta c_{i j} w_{i j} \\
& \text { s.t. } \sum_{j \in N \backslash\{i\}} x_{i j}-x_{j i}+w_{i j}-w_{j i}=0 \quad \forall i \in N \\
& x_{i j} \geq r_{i j}^{S} \quad \forall i j \in A \\
& x_{i j}, w_{i j} \in \mathbb{N} \cup\{0\} \quad \forall i j \in A
\end{aligned}
$$

where $x_{i j}$ and $w_{i j}$ denote the number of times lane $i j$ is traversed with and without service respectively. We denote an optimal solution for the above problem with $\left(x_{i j}^{S} ; w_{i j}^{S}\right)_{i j \in A}$. Model 1 corresponds to a minimum-cost circulation problem with its constraints forming a totally unimodular matrix (Schrijver, 1998). Thus with integer requirement vectors, the linear relaxation of Model 1 does not affect the optimal solution. 
The dual associated with the linear relaxation of Model 1 for $P$ is

$$
\begin{aligned}
& \text { Model 2: } \quad d^{\Gamma}=\max \sum_{i j \in L} r_{i j}^{P} I_{i j} \\
& \begin{array}{ll}
\text { s.t. } I_{i j}+y_{i}-y_{j} \leq c_{i j} & \forall i j \in A \\
y_{i}-y_{j} \leq \theta c_{i j} & \forall i j \in A \\
I_{i j} \geq 0 & \forall i j \in A
\end{array}
\end{aligned}
$$

where $L=\left\{i j \mid r_{i j}>0\right\}$ is the set of required lanes. Let $I^{\Gamma}=\left(I_{i j}^{\Gamma}\right)_{i j \in A}$ be an optimal solution for $d^{\Gamma}$. For a required lane $i j \in L, I_{i j}^{\Gamma}$ gives the shadow price that determines the amount of decrease in $z^{\Gamma}(P)$ resulting from reducing $r_{i j}^{P}$ by one. We denote the set of all solutions to $d^{\Gamma}$ with $\boldsymbol{I}^{\Gamma}$.

\section{Core and Dual Allocations}

Given $P$, an allocation $\beta=\left(\beta^{k}\right)_{k \in P}$ is a vector containing a real number for every player in $P$. The allocation $\beta$ is in the core of the game $(P, z)$ if and only if it is efficient, i.e. $\sum_{k \in P} \beta^{k}=z(P)$, and stable, i.e. $\sum_{k \in S} \beta^{k} \leq z(S)$ for all $S \subset P$.

Owen (1975) introduces the class of linear production games and shows that an allocation in the core of these games can be obtained from a solution to the dual problem. As discussed in Özener and Ergun (2008), the game $\left(P, z^{\Gamma}\right)$ with $z^{\Gamma}(S)$ defined by the LP-relaxation of Model 1 for every $S \subseteq P$ is an instance of the class of linear production games. Thus, an allocation in the core of $\left(P, z^{\Gamma}\right)$ can be obtained from a dual solution in the following manner:

$$
\beta^{k}=\sum_{i j \in L} r_{i j}^{k} I_{i j}^{\Gamma}, \quad \forall k \in P .
$$

Thus, in LCGs every dual solution obtains an allocation in the core. The question concerning a complete characterization of core via dual solutions addresses the reverse of the latter, i.e. does every core allocation correspond to a dual solution?

\section{LCGs with General Shippers}

In this section we show that a complete characterization of the core via duals is not possible if some players have multiple service requirements (general shippers). The following example shows that this is the case even if every lane requires service at most once.

Example 1. Consider the lane covering situation associated with the graph in Figure 1. The service costs across lanes with opposite directions are symmetric and are given in the figure. We let $\theta=1$. Consider two players $P=\{A, B\}$ with player $A$ requiring service on lanes 12 and 13 , and player $B$ requiring service along the lane 41 . We have $z^{\Gamma}(\{A\})=z^{\Gamma}(\{B\})=8$, and $z^{\Gamma}(P)=13$. Observe that the core of $\left(P, z^{\Gamma}\right)$ is completely characterized by the allocations $\beta=\left(\beta^{A}, \beta^{B}\right)=(8-\epsilon, 5+\epsilon)$ with $0 \leq \epsilon \leq 3$. In every dual solution for this situation it holds that $I_{12}^{\Gamma}=4, I_{13}^{\Gamma}=4, I_{41}^{\Gamma}=5$. Thus, the allocation obtained from the dual solutions is unique and equivalent to $\beta^{A}=8$ and $\beta^{B}=5 . \triangle$ 


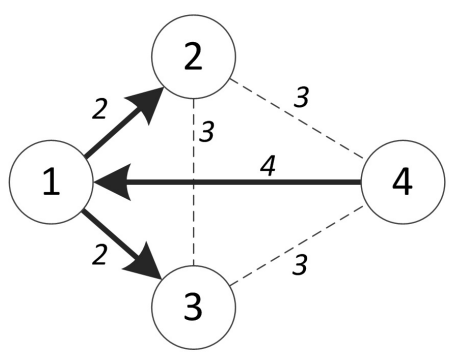

Figure 1: The network in Example 1

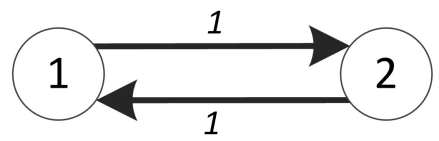

Figure 2: The network in Example 2

The next example illustrates that with general shippers a complete characterisation of the core via duals also fails even if the requirements of all shippers are separated on lanes such that no shipper requires service along more than one lane.

Example 2. Consider the lane covering situation associated with the graph in Figure 2 and three players $P=\{A, B, C\}$ where both players $A$ and $B$ require a single service along the lane 12 and player $C$ requires service along the lane 21 twice. Let $c_{12}=c_{21}=\theta=1$. We have $z^{\Gamma}(S)=2$ if $S \in\{\{A\},\{B\}\}$ and $z^{\Gamma}(S)=4$ for all other $S \subseteq N, S \neq \varnothing$. It is straightforward to check that the allocation $\beta=\left(\beta^{A}, \beta^{B}, \beta^{C}\right)=(1.5,0.5,2)$ belongs to the core. However, in every allocation obtained via duals from (9) it holds that $\beta^{A}=\beta^{B}=I_{12}^{\Gamma} . \triangle$

The above example demonstrates that in LCGs, core allocations might give unequal costs to shippers who require service on the same lane. These allocations are unobtainable via dual solutions.

\section{$5 \quad$ LCGs with Simple Shippers}

In the rest of this section we assume that $\Gamma$ is a lane covering situation where all players are simple shippers. We show that in these situations dual solutions completely characterize the core. For this purpose, we introduce additional notation.

Given a situation $\Gamma$, an optimal solution $\left(x_{i j}^{S} ; w_{i j}^{S}\right)_{i j \in A}$ to Model 1 for $S \subseteq P$ induces a directed multigraph $\mathcal{G}(S)=(N, \mathcal{A}(S))$ where for any $i j \in A$, the $\mathcal{A}(S)$ contains $x_{i j}^{S}$ number of lanes with cost $c_{i j}$, i.e. type $x$ (service) lanes, and $w_{i j}^{S}$ number of lanes with cost $\theta c_{i j}$, i.e. type $w$ (repositioning) lanes, from $i$ to $j$. Without loss of generality, hereafter we consider optimal solutions where $x_{i j}^{S}=r_{i j}^{S}$ for all $i j \in A$. A simple cycle on $\mathcal{G}(S)$ is defined as a sequence of nodes $n_{0}, \ldots, n_{t}$ and lanes, such that all nodes are non-identical except for $n_{0}=n_{t}$ and there exists exactly one lane (of either type $x$ or $w$ ) between any consecutive pair of nodes. Constraint (2) in Model 1 ensures that for every node $i \in N$ the number of lanes in $\mathcal{A}(S)$ 
whose end nodes are $i$ is equal to the number of lanes whose start nodes are $i$. Therefore, by Veblen's theorem (Bondy and Murty, 2008), the $\mathcal{A}(S)$ can be decomposed into a set of simple cycles. Let $\mathscr{C}^{S}$ be such a decomposition. We refer to $\mathscr{C}^{S}$ as a decomposition of an optimal service plan for coalition $S$ into simple cycles. We denote a simple cycle in $\mathscr{C}^{S}$ by $C=\left(C^{x} ; C^{w}\right)$ where $C^{x}=\left(C_{i j}^{x}\right)_{i j \in A}$ and $C^{w}=\left(C_{i j}^{w}\right)_{i j \in A}$ are vectors containing type $x$ and type $w$ lanes of $C$ respectively. Note that by definition of simple cycles we have $C_{i j}^{x}, C_{i j}^{w} \in\{0,1\}$ for all $i j \in A$. The cost of a simple cycle $C \in \mathscr{C}^{S}$ is $\lambda_{C}=\sum_{i j \in A} c_{i j} C_{i j}^{x}+\theta c_{i j} C_{i j}^{w}$. Accordingly, we have $z^{\Gamma}(S)=\sum_{C \in \mathscr{C} S} \lambda_{C}$.

Given $C \in \mathscr{C}^{P}$, we define $S_{C}=\left\{S \subseteq P \mid \sum_{k \in S} r^{k}=C^{x}\right\}$ as a set of serviced shippers in $C$. Note that $S_{C}$ is not necessarily unique. The following lemma states that the cost of a simple cycle $C \in \mathscr{C}^{P}$ equals the cost of the coalition of a set of serviced shippers in $C$.

Lemma 1. Let $\mathscr{C}^{P}$ be a decomposition of an optimal service plan for coalition $P$ into simple cycles. For all $C \in \mathscr{C}^{P}$ and any $S_{C}$ we have $\lambda_{C}=z^{\Gamma}\left(S_{C}\right)$.

Proof. Clearly $\lambda_{C} \geq z^{\Gamma}\left(S_{C}\right)$ since any set of serviced shippers in $C$, i.e. $S_{C}$, can together use $C$ for covering their required lanes. On the other hand, $\lambda_{C}>z^{\Gamma}\left(S_{C}\right)$ implies that $\mathscr{C}^{P} \ni C$ does not correspond to an optimal solution as in this case replacing $C$ with $\mathscr{C}^{S_{C}}$ would result in a lower total cost. Therefore $\lambda_{C}=z^{\Gamma}\left(S_{C}\right)$.

Next, we show that any allocation in the core divides the entire cost of a simple cycle $C \in \mathscr{C}^{P}$ among a set of serviced shippers in $C$.

Lemma 2. Let $\left(\beta^{k}\right)_{k \in P}$ be an allocation in the core of $\left(P, z^{\Gamma}\right)$ and $\mathscr{C}^{P}$ be a decomposition of an optimal service plan for coalition $P$ into simple cycles. For all $C \in \mathscr{C}^{P}$ and any $S_{C}$ we have $\sum_{k \in S_{C}} \beta^{k}=z^{\Gamma}\left(S_{C}\right)$.

Proof. By Lemma 1, it suffices to show that $\sum_{k \in S_{C}} \beta^{k}=\lambda_{C}$. Since $\left(\beta^{k}\right)_{k \in P}$ is a core allocation, it holds that $\sum_{k \in S_{C}} \beta^{k} \leq \lambda_{C}$. Fix a $S_{C}$ and consider the rest of the players, $P \backslash S_{C}$. A core allocation satisfies $\sum_{k \in P \backslash S_{C}} \beta^{k} \leq \sum_{C^{\prime} \in \mathscr{C} P \backslash C} \lambda_{C^{\prime}}$. We have

$$
\sum_{k \in S_{C}} \beta^{k}=\sum_{k \in P} \beta^{k}-\sum_{k \in P \backslash S_{C}} \beta^{k} \geq \sum_{C^{\prime} \in \mathscr{C}^{P}} \lambda_{C^{\prime}}-\sum_{C^{\prime} \in \mathscr{C}^{P} \backslash C} \lambda_{C^{\prime}}=\lambda_{C}
$$

Therefore, it must be the case that $\sum_{k \in S_{C}} \beta^{k}=\lambda_{C}$.

We are now ready to show that any allocation in core gives equal costs to players requiring the same lane.

Theorem 1. Let $l, l^{\prime} \in P$ be such that $r^{l}=r^{l^{\prime}}$. Let $\left(\beta^{k}\right)_{k \in P}$ be an allocation in the core of $\left(P, z^{\Gamma}\right)$. We have $\beta^{l}=\beta^{l^{\prime}}$.

Proof. Let $\mathscr{C}^{P}$ be a decomposition of an optimal service plan for coalition $P$ into simple cycles. Consider $C \in \mathscr{C}^{P}$ and $S_{C}$ such that $l \in S_{C}$. Since $r^{l}=r^{l^{\prime}}$, by definition of $S_{C}$ it holds that $\sum_{k \in S_{C}} r^{k}-r^{l}+r^{l^{\prime}}=C^{x}$. Thus, $S_{C}^{\prime}=S_{C} \backslash\{l\} \cup\left\{l^{\prime}\right\}$ also corresponds to a set of serviced shippers in $C$. By Lemma 2, we have $\sum_{k \in S_{C}} \beta^{k}=\sum_{k \in S_{C}^{\prime}} \beta^{k}=\lambda_{C}$ which obtains $\beta^{l}=\beta^{l^{\prime}}$. 
Before presenting the main result of this section, we highlight the following property of LCGs.

Lemma 3. Let $\beta=\left(\beta^{k}\right)_{k \in P}$ be an allocation in the core of a $L C G$ with simple shippers only. We have $\beta^{k} \geq 0$ for all $k \in P$.

Proof. Suppose $\beta$ is an allocation in the core such that for player $l \in P$ it holds that $\beta^{l}<0$. By efficiency it must be that $\sum_{k \in P \backslash\{l\}} \beta^{k}>z^{\Gamma}(P)$. Since $\beta$ is in the core, we have $\sum_{k \in P \backslash\{l\}} \beta^{k} \leq$ $z^{\Gamma}(P \backslash\{l\})$. Therefore it must hold that $z^{\Gamma}(P)<z^{\Gamma}(P \backslash\{l\})$. As every optimal solution to $z^{\Gamma}(P)$ is a feasible solution to $z^{\Gamma}(P \backslash\{l\})$, the latter inequality is impossible for any LCG. Therefore, we must have $\beta^{l} \geq 0$ and consequently $\beta^{k} \geq 0$ for all $k \in P$.

We are now ready to provide the main result of this section.

Theorem 2. Let $\Gamma$ be a lane covering situation. If all players in $\Gamma$ are simple, then the core of $\left(P, z^{\Gamma}\right)$ is completely characterized by the set of corresponding dual solutions.

Proof. Let $I=\left(I_{i j}\right)_{i j \in A}$ be a vector of variables defined over the lanes in $A$. It directly follows from Theorem 1 and Lemma 3 that with simple shippers only, all allocations in the core are of the form $\beta=\left(\sum_{i j \in A} r_{i j}^{k} I_{i j}\right)_{k \in P}$ for some $I=\left(I_{i j}\right)_{i j \in A}$ with $I_{i j} \geq 0$ for all $i j \in A$. Hence, it suffices to show that if $\beta$ is in the core, then $I \in \boldsymbol{I}^{\Gamma}$. We first show that if $\beta$ is in the core, then the following program is feasible:

$$
\begin{aligned}
& \text { Model 3: } \quad \min \sum_{i j \in A}\left(c_{i j}-I_{i j}\right) x_{i j}+\theta c_{i j} w_{i j} \\
& \text { s.t. } \sum_{j \in N \backslash\{i\}} x_{i j}-x_{j i}+w_{i j}-w_{j i}=0 \quad \forall i \in N \\
& x_{i j}, w_{i j} \geq 0 \quad \forall i j \in A
\end{aligned}
$$

Since $\left(x_{i j}^{P} ; w_{i j}^{P}\right)_{i j \in A}$ is a feasible solution to Model 3 , we need to show that the latter program is not unbounded. Note that Model 3 corresponds to a minimum-cost circulation problem on a network with reduced service costs wherein all type $x$ lanes from $i$ to $j$ have the cost $c_{i j}-I_{i j}$ and all type $w$ lanes from $i$ to $j$ have the cost $\theta c_{i j}$. The cost of a simple cycle $C$ on this network is $\tilde{\lambda}_{C}=\sum_{i j \in A}\left(c_{i j}-I_{i j}\right) C_{i j}^{x}+\theta c_{i j} C_{i j}^{w}$. Suppose that the program is unbounded. If this is the case, then a cycle could be constructed on this network such that $\tilde{\lambda}_{C}<0$. The latter implies that $\lambda_{C}<\sum_{i j \in A} I_{i j} C_{i j}^{x}$. Since $z^{\Gamma}\left(S_{C}\right) \leq \lambda_{C}$ it must be that $z^{\Gamma}\left(S_{C}\right)<\sum_{i j \in A} I_{i j} C_{i j}^{x}=\sum_{k \in S_{C}} \sum_{i j \in A} r_{i j}^{k} I_{i j}=\sum_{k \in S_{C}} \beta^{k}$ which is possible only if $\beta$ is not stable, a contradiction. We conclude that if $\beta$ is in the core, then the program in Model 3 is feasible. Next, observe that the dual solution to Model 3 is characterized by the following constraints:

$$
\begin{array}{rr}
y_{i}-y_{j} \leq c_{i j}-I_{i j} & \forall i j \in A \\
y_{i}-y_{j} \leq \theta c_{i j} & \forall i j \in A
\end{array}
$$

From the first step it follows that if $\beta$ is a stable allocation, then the program in Model 3 is feasible which indicates that a vector $y=\left(y_{i}\right)_{i \in N}$ can be found such that constraints in (13) and (14) are satisfied. This in conjunction with the fact that $I_{i j} \geq 0$ for all $i j \in A$ and considering that $\sum_{k \in P} \sum_{i j \in A} r_{i j}^{k} I_{i j}=\sum_{i j \in A} r^{P} I_{i j}=z^{\Gamma}(P)$ yield that $I \in \boldsymbol{I}^{\Gamma}$. 


\begin{tabular}{ccc} 
& \multicolumn{1}{c}{$\begin{array}{c}\text { Every lane is required } \\
\text { by at most one shipper }\end{array}$} & $\begin{array}{c}\text { Some lanes are required } \\
\text { by multiple shippers }\end{array}$ \\
\cline { 2 - 3 } Every shipper requires & Possible (Theorem 2) & Possible (Theorem 2) \\
at most one lane & & \\
\cline { 2 - 3 } $\begin{array}{c}\text { Some shippers require } \\
\text { multiple lanes }\end{array}$ & Impossible (Example 1) & Impossible (Example 2) \\
\cline { 2 - 3 } & &
\end{tabular}

Table 1: Possibility of a complete characterization of the core via duals in LCG

\section{Concluding Remarks}

In this note we extended the analysis of LCGs with respect to the possibilities of a complete characterization of the core via dual solutions. Instead of considering lanes as surrogate players, which is the case in Özener and Ergun (2008), we allowed shippers to be the players. Accordingly, we delineated the situations wherein a complete characterization of the core via duals are possible. An overview of the results are given in Table 1. As we proved, such a characterization is possible if each shipper has at most one service requirement. In this case, the dual solutions could completely characterize the core even if multiple shippers require service along the same lane. However, multiplicity of shippers' service requirement hinder such a complete characterization, even if multiple service requirements of each shipper is along a single lane. In conclusion, our analysis shows that focusing solely on the allocations obtained via dual solutions could significantly limit the number of options for choosing "fair" allocations in LCGs.

\section{References}

A. Bondy and U.S.R. Murty. Graph Theory. Springer, 2008.

Q. Fang, S. Zhu, M. Cai, and X. Deng. On computational complexity of membership test in flow games and linear production games. International Journal of Game Theory, 31(1): $39-45,2002$.

E. Kalai and E. Zemel. Generalized network problems yielding totally balanced games. Operations Research, 30(5):998-1008, 1982.

G. Owen. On the core of linear production games. Mathematical programming, 9(1):358-370, 1975.

O.Ö. Özener and Ö. Ergun. Allocating costs in a collaborative transportation procurement network. Transportation Science, 42(2):146-165, 2008.

A. Schrijver. Theory of linear and integer programming. Wiley, 1998. 
Working Papers Beta 2009 - 2013

nr. Year Title

4392013 On Characterization of the Core of Lane Covering

Games via Dual Solutions

4382013 Destocking, the Bullwhip Effect, and the Credit Crisis: Empirical Modeling of Supply Chain Dynamics

4372013 Methodological support for business process Redesign in healthcare: a systematic literature review

4362013 Dynamics and equilibria under incremental Horizontal differentiation on the Salop circle

4352013 Analyzing Conformance to Clinical Protocols $\underline{\text { Involving Advanced Synchronizations }}$

4342013 Models for Ambulance Planning on the Strategic and the Tactical Level

4332013 Mode Allocation and Scheduling of Inland Container Transportation: A Case-Study in the Netherlands

4322013 Socially responsible transportation and lot sizing: Insights from multiobjective optimization

4312013 Inventory routing for dynamic waste collection

4302013 Simulation and Logistics Optimization of an Integrated Emergency Post

4292013 Last Time Buy and Repair Decisions for Spare Parts
Author(s)

Behzad Hezarkhani, Marco Slikker, Tom van Woensel

Maximiliano Udenio, Jan C. Fransoo, Robert Peels

Rob J.B. Vanwersch, Khurram Shahzad, Irene Vanderfeesten, Kris Vanhaecht, Paul Grefen, Liliane Pintelon, Jan Mendling, Geofridus G. Van Merode, Hajo A. Reijers

B. Vermeulen, J.A. La Poutré, A.G. de Kok

Hui Yan, Pieter Van Gorp, Uzay Kaymak, Xudong Lu, Richard Vdovjak, Hendriks H.M. Korsten, Huilong Duan

J. Theresia van Essen, Johann L. Hurink, Stefan Nickel, Melanie Reuter

Stefano Fazi, Tom Van Woensel, Jan C. Fransoo

Yann Bouchery, Asma Ghaffari, Zied Jemai, Jan Fransoo

Martijn Mes, Marco Schutten, Arturo Pérez Rivera

N.J. Borgman, M.R.K. Mes, I.M.H. Vliegen, E.W. Hans

S. Behfard, M.C. van der Heijden, A. Al Hanbali, W.H.M. Zijm 
4282013 A Review of Recent Research on Green Road Freight Transportation

4272013 Typology of Repair Shops for Maintenance Spare Parts

4262013 A value network development model and Implications for innovation and production network management

4252013 Single Vehicle Routing with Stochastic Demands: Approximate Dynamic Programming

4242013 Influence of Spillback Effect on Dynamic Shortest Path Problems with Travel-Time-Dependent Network Disruptions

4232013 Dynamic Shortest Path Problem with Travel-TimeDependent Stochastic Disruptions: Hybrid Approximate Dynamic Programming Algorithms with a Clustering Approach

4222013 System-oriented inventory models for spare parts

Lost Sales Inventory Models with Batch Ordering 4212013 And Handling Costs

4202013 Response speed and the bullwhip

4192013 Anticipatory Routing of Police Helicopters

4182013 Supply Chain Finance. A conceptual framework to advance research

4172013 Improving the Performance of Sorter Systems By Scheduling Inbound Containers

4162013 Regional logistics land allocation policies: Stimulating spatial concentration of logistics firms
Emrah Demir, Tolga Bektas, Gilbert Laporte

M.A. Driessen, V.C.S. Wiers, G.J. van Houtum, W.D. Rustenburg

B. Vermeulen, A.G. de Kok
Derya Sever, Nico Dellaert, Tom Van Woensel, Ton de Kok

Derya Sever, Lei Zhao, Nico Dellaert, Tom Van Woensel, Ton de Kok

R.J.I. Basten, G.J. van Houtum

T. Van Woensel, N. Erkip, A. Curseu, J.C. Fransoo

Maximiliano Udenio, Jan C. Fransoo, Eleni Vatamidou, Nico Dellaert

Rick van Urk, Martijn R.K. Mes, Erwin W. Hans

Kasper van der Vliet, Matthew J. Reindorp, Jan C. Fransoo

S.W.A. Haneyah, J.M.J. Schutten, K. Fikse

Frank P. van den Heuvel, Peter W. de Langen, Karel $\mathrm{H}$. van Donselaar, Jan C. Fransoo 
4152013 The development of measures of process harmonization

4142013 BASE/X. Business Agility through CrossOrganizational Service Engineering

4132013 The Time-Dependent Vehicle Routing Problem with Soft Time Windows and Stochastic Travel $\underline{\text { Times }}$

4122013 Clearing the Sky - Understanding SLA Elements in Cloud Computing

4112013 Approximations for the waiting time distribution In an $M / G / c$ priority queue

$4102013 \frac{\text { To co-locate or not? Location decisions and }}{\text { logistics concentration areas }}$

4092013 The Time-Dependent Pollution-Routing Problem

$4082013 \frac{\text { Scheduling the scheduling task: A time }}{\text { Management perspective on scheduling }}$

$4072013 \frac{\text { Clustering Clinical Departments for Wards to }}{\text { Achieve a Prespecified Blocking Probability }}$

$4062013 \frac{\text { MyPHRMachines: Personal Health Desktops }}{\text { in the Cloud }}$ 4052013 Maximising the Value of Supply Chain Finance $4042013 \frac{\text { Reaching } 50 \text { million nanostores: retail }}{\text { distribution in emerging megacities }}$ $4032013 \frac{\text { A Vehicle Routing Problem with Flexible Time }}{\underline{\text { Windows }}}$
Heidi L. Romero, Remco M. Dijkman, Paul W.P.J. Grefen, Arjan van Weele

Paul Grefen, Egon Lüftenegger, Eric van der Linden, Caren Weisleder

Duygu Tas, Nico Dellaert, Tom van Woensel, Ton de Kok

Marco Comuzzi, Guus Jacobs, Paul Grefen

A. Al Hanbali, E.M. Alvarez, M.C. van der van der Heijden

Frank P. van den Heuvel, Karel H. van Donselaar, Rob A.C.M. Broekmeulen, Jan C. Fransoo, Peter W. de Langen

Anna Franceschetti, Dorothée Honhon, Tom van Woensel, Tolga Bektas, GilbertLaporte.

J.A. Larco, V. Wiers, J. Fransoo

J. Theresia van Essen, Mark van Houdenhoven, Johann L. Hurink

Pieter Van Gorp, Marco Comuzzi

Kasper van der Vliet, Matthew J. Reindorp, Jan C. Fransoo

Edgar E. Blanco, Jan C. Fransoo

Duygu Tas, Ola Jabali, Tom van Woensel 
4022012 The Service Dominant Business Model: A

Service Focused Conceptualization

$401 \quad$ Relationship between freight accessibility and 2012 Logistics employment in US counties

4002012 A Condition-Based Maintenance Policy for MultiComponent Systems with a High Maintenance Setup Cost

3992012 A flexible iterative improvement heuristic to Support creation of feasible shift rosters in Self-rostering

Scheduled Service Network Design with 3982012 Synchronization and Transshipment Constraints For Intermodal Container Transportation Networks

3972012 Destocking, the bullwhip effect, and the credit Crisis: empirical modeling of supply chain Dynamics

3962012 Vehicle routing with restricted loading capacities

3952012 Service differentiation through selective lateral transshipments

3942012 A Generalized Simulation Model of an Integrated Emergency Post

3932012 Business Process Technology and the Cloud: Defining a Business Process Cloud Platform

3922012 Vehicle Routing with Soft Time Windows and Stochastic Travel Times: A Column Generation
Egon Lüftenegger, Marco Comuzzi, Paul Grefen, Caren Weisleder

Frank P. van den Heuvel, Liliana Rivera,Karel H. van Donselaar, Ad de Jong, Yossi Sheffi, Peter W. de Langen, Jan C.Fransoo

Qiushi Zhu, Hao Peng, Geert-Jan van Houtum

E. van der Veen, J.L. Hurink, J.M.J. Schutten, S.T. Uijland

K. Sharypova, T.G. Crainic, T. van Woensel, J.C. Fransoo

Maximiliano Udenio, Jan C. Fransoo, Robert Peels

J. Gromicho, J.J. van Hoorn, A.L. Kok J.M.J. Schutten

E.M. Alvarez, M.C. van der Heijden, I.M.H. Vliegen, W.H.M. Zijm

Martijn Mes, Manon Bruens

Vasil Stoitsev, Paul Grefen

D. Tas, M. Gendreau, N. Dellaert, T. van Woensel, A.G. de Kok 


\section{And Branch-and-Price Solution Approach}

$3912012 \underline{\text { Improve OR-Schedule to Reduce Number of }}$ $\underline{\text { Required Beds }}$

How does development lead time affect

3902012 performance over the ramp-up lifecycle?

\section{Evidence from the consumer electronics}

3892012 industry

The Impact of Product Complexity on Ramp-

3882012 Up Performance

Co-location synergies: specialized versus diverse 3872012 logistics concentration areas

Proximity matters: Synergies through co-location 3862012 of logistics establishments

Spatial concentration and location dynamics in 3852012 logistics:the case of a Dutch province

3842012 FNet: An Index for Advanced Business Process Querying

3832012 Defining Various Pathway Terms

3822012 The Service Dominant Strategy Canvas: Defining and Visualizing a Service Dominant Strategy through the Traditional Strategic Lens

3812012 A Stochastic Variable Size Bin Packing Problem With Time Constraints
J.T. v. Essen, J.M. Bosch, E.W. Hans,

M. v. Houdenhoven, J.L. Hurink

Andres Pufall, Jan C. Fransoo, Ad de Jong

Andreas Pufall, Jan C. Fransoo, Ad de Jong, Ton de Kok

Frank P.v.d. Heuvel, Peter W.de Langen,

Karel H. v. Donselaar, Jan C. Fransoo

Frank P.v.d. Heuvel, Peter W.de Langen,

Karel H. v.Donselaar, Jan C. Fransoo

Frank P. v.d. Heuvel, Peter W.de Langen,

Karel H.v. Donselaar, Jan C. Fransoo

Zhiqiang Yan, Remco Dijkman, Paul Grefen

W.R. Dalinghaus, P.M.E. Van Gorp

Egon Lüftenegger, Paul Grefen, Caren Weisleder

Stefano Fazi, Tom van Woensel, Jan C. Fransoo

K. Sharypova, T. van Woensel, J.C. Fransoo 
Coordination and Analysis of Barge Container 3802012 Hinterland Networks

3792012 Proximity matters: Synergies through co-location of logistics establishments

3782012 A literature review in process harmonization: a conceptual framework $3772012 \frac{\text { A Generic Material Flow Control Model for }}{\underline{\text { Two Different Industries }}}$

3752012 Improving the performance of sorter systems by scheduling inbound containers

3742012 Strategies for dynamic appointment making by container terminals

3732012 MyPHRMachines: Lifelong Personal Health Records in the Cloud

3722012 Service differentiation in spare parts supply through dedicated stocks

3712012 Spare parts inventory pooling: how to share the benefits

3702012 Condition based spare parts supply

3692011 Using Simulation to Assess the Opportunities of Dynamic Waste Collection

3682011 Aggregate overhaul and supply chain planning for $\underline{\text { rotables }}$

3672011 Operating Room Rescheduling

3662011 Switching Transport Modes to Meet Voluntary Carbon Emission Targets
Frank P. van den Heuvel, Peter W. de Langen, Karel $\mathrm{H}$. van Donselaar, Jan C.

Fransoo

Heidi Romero, Remco Dijkman, Paul Grefen, Arjan van Weele

S.W.A. Haneya, J.M.J. Schutten, P.C. Schuur, W.H.M. Zijm

H.G.H. Tiemessen, M. Fleischmann, G.J. van Houtum, J.A.E.E. van Nunen, E. Pratsini

Albert Douma, Martijn Mes

Pieter van Gorp, Marco Comuzzi

E.M. Alvarez, M.C. van der Heijden, W.H.M. Zijm

Frank Karsten, Rob Basten

X.Lin, R.J.I. Basten, A.A. Kranenburg, G.J. van Houtum

Martijn Mes

J. Arts, S.D. Flapper, K. Vernooij

J.T. van Essen, J.L. Hurink, W. Hartholt,

B.J. van den Akker

Kristel M.R. Hoen, Tarkan Tan, Jan C. Fransoo, Geert-Jan van Houtum

Elisa Alvarez, Matthieu van der Heijden 
3652011 On two-echelon inventory systems with Poisson demand and lost sales $3642011 \frac{\text { Minimizing the Waiting Time for Emergency }}{\underline{\text { Surgery }}}$

3632011 Vehicle Routing Problem with Stochastic Travel Times Including Soft Time Windows and Service Costs

3622011 A New Approximate Evaluation Method for TwoEchelon Inventory Systems with Emergency Shipments

3612011

Approximating Multi-Objective Time-Dependent Optimization Problems

3602011 Branch and Cut and Price for the Time Dependent Vehicle Routing Problem with Time Window

3592011 Analysis of an Assemble-to-Order System with Different Review Periods

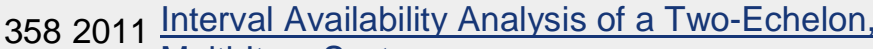
Multi-Item System

$3572011 \underline{\text { Carbon-Optimal and Carbon-Neutral Supply }}$

Generic Planning and Control of Automated

3562011 Material Handling Systems: Practical Requirements Versus Existing Theory

3552011 Last time buy decisions for products sold under warranty

3542011

Spatial concentration and location dynamics in 2011 logistics: the case of a Dutch provence

353

Identification of Employment Concentration Areas

3522011

BOMN 2.0 Execution Semantics Formalized as Graph Rewrite Rules: extended version
J.T. van Essen, E.W. Hans, J.L. Hurink A. Oversberg

Duygu Tas, Nico Dellaert, Tom van Woensel, Ton de Kok

Erhun Özkan, Geert-Jan van Houtum, Yasemin Serin

Said Dabia, El-Ghazali Talbi, Tom Van Woensel, Ton de Kok

Said Dabia, Stefan Röpke, Tom Van Woensel, Ton de Kok

A.G. Karaarslan, G.P. Kiesmüller, A.G. de Kok

Ahmad Al Hanbali, Matthieu van der Heijden

Felipe Caro, Charles J. Corbett, Tarkan Tan, Rob Zuidwijk

Sameh Haneyah, Henk Zijm, Marco Schutten, Peter Schuur

M. van der Heijden, B. Iskandar

Frank P. van den Heuvel, Peter W. de Langen, Karel $\mathrm{H}$. van Donselaar, Jan C. Fransoo

Frank P. van den Heuvel, Peter W. de Langen, Karel $\mathrm{H}$. van Donselaar, Jan C. Fransoo

Pieter van Gorp, Remco Dijkman

Frank Karsten, Marco Slikker, GeertJan van Houtum

E. Lüftenegger, S. Angelov, P. Grefen 
2011 independent service providers

2011

350 A Framework for Business Innovation Directions 2011

349 The Road to a Business Process Architecture: An Overview of Approaches and their Use

3482011

Effect of carbon emission regulations on transport mode selection under stochastic demand

3472011 An improved MIP-based combinatorial approach for a multi-skill workforce scheduling problem

3462011 An approximate approach for the joint problem of level of repair analysis and spare parts stocking

3452011 Joint optimization of level of repair analysis and spare parts stocks $344 \frac{\text { Inventory control with manufacturing lead time }}{\text { flexibility }}$

2011 Analysis of resource pooling games via a new 343 extenstion of the Erlang loss function

3422010 Vehicle refueling with limited resources

$341 \quad$ Optimal Inventory Policies with Non-stationary 2010 Supply Disruptions and Advance Supply Information

3392010 Redundancy Optimization for Critical Components in High-Availability Capital Goods

338 Analysis of a two-echelon inventory system with 2010 two supply modes

Kurtulus Baris Öner, Alan Scheller-Wolf Geert-Jan van Houtum

Joachim Arts, Gudrun Kiesmüller Murat Firat, Gerhard J. Woeginger

3352010 Analysis of the dial-a-ride problem of Hunsaker and Savelsbergh

Murat Firat, Cor Hurkens

$334 \quad$ Attaining stability in multi-skill workforce scheduling A.J.M.M. Weijters, J.T.S. Ribeiro 2010 
$333 \quad$ Flexible Heuristics Miner (FHM) 2010

332 An exact approach for relating recovering surgical 2010 patient workload to the master surgical schedule

3312010

Efficiency evaluation for pooling resources in health care

The Effect of Workload Constraints in

Mathematical Programming Models for Production

3302010 Planning

Using pipeline information in a multi-echelon spare 3292010 parts inventory system

Reducing costs of repairable spare parts supply 3282010 systems via dynamic scheduling

Identification of Employment Concentration and 3272010

Specialization Areas: Theory and Application

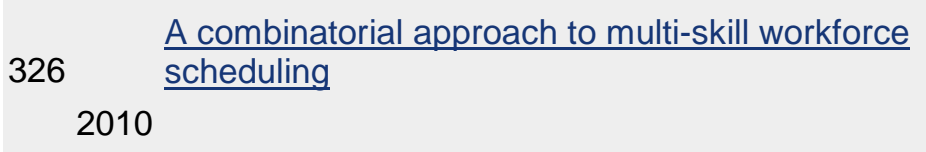

Stability in multi-skill workforce scheduling

325

2010

Maintenance spare parts planning and control: A

324 framework for control and agenda for future 2010 research

Near-optimal heuristics to set base stock levels in a two-echelon distribution network

323

2010

Inventory reduction in spare part networks by

3222010 selective throughput time reduction

The selective use of emergency shipments for 3212010 service-contract differentiation
P.T. Vanberkel, R.J. Boucherie, E.W. Hans, J.L. Hurink, W.A.M. van Lent, W.H. van Harten

Peter T. Vanberkel, Richard J.

Boucherie, Erwin W. Hans, Johann L. Hurink, Nelly Litvak

M.M. Jansen, A.G. de Kok, I.J.B.F. Adan

Christian Howard, Ingrid Reijnen, Johan Marklund, Tarkan Tan

H.G.H. Tiemessen, G.J. van Houtum

F.P. van den Heuvel, P.W. de Langen, K.H. van Donselaar, J.C. Fransoo

Murat Firat, Cor Hurkens

Murat Firat, Cor Hurkens, Alexandre Laugier

M.A. Driessen, J.J. Arts, G.J. v. Houtum, W.D. Rustenburg, B. Huisman

R.J.I. Basten, G.J. van Houtum

M.C. van der Heijden, E.M. Alvarez, J.M.J. Schutten

E.M. Alvarez, M.C. van der Heijden, W.H. Zijm

B. Walrave, K. v. Oorschot, A.G.L. Romme 
Nico Dellaert, Jully Jeunet.

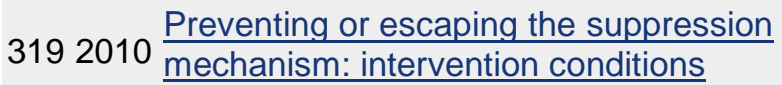

R. Seguel, R. Eshuis, P. Grefen.

Hospital admission planning to optimize major

3182010 resources utilization under uncertainty

Minimal Protocol Adaptors for Interacting Services

Tom Van Woensel, Marshall L. Fisher, Jan C. Fransoo.

3172010

Teaching Retail Operations in Business and

Engineering Schools

Lydie P.M. Smets, Geert-Jan van Houtum, Fred Langerak.

3162010

Design for Availability: Creating Value for

Manufacturers and Customers

3152010

Transforming Process Models: executable rewrite rules versus a formalized Java program

Bob Walrave, Kim E. van Oorschot, A. Georges L. Romme

3142010

Getting trapped in the suppression of exploration: A simulation model

A Dynamic Programming Approach to MultiObjective Time-Dependent Capacitated Single Vehicle Routing Problems with Time Windows

Tales of a So(u)rcerer: Optimal Sourcing Decisions 3122010 Under Alternative Capacitated Suppliers and General Cost Structures

In-store replenishment procedures for perishable

3112010 inventory in a retail environment with handling costs and storage constraints $3102010 \frac{\text { The state of the art of innovation-driven business }}{\text { models in the financial services industry }}$

S. Dabia, T. van Woensel, A.G. de Kok

3092010 Design of Complex Architectures Using a Three Dimension Approach: the CrossWork Case

3082010 Effect of carbon emission regulations on transport mode selection in supply chains

3072010 Interaction between intelligent agent strategies for real-time transportation planning

3062010 Internal Slackening Scoring Methods

3052010 Vehicle Routing with Traffic Congestion and Drivers' Driving and Working Rules

3042010 Practical extensions to the level of repair analysis

Osman Alp, Tarkan Tan

R.A.C.M. Broekmeulen, C.H.M. Bakx

E. Lüftenegger, S. Angelov, E. van der Linden, P. Grefen

R. Seguel, P. Grefen, R. Eshuis

K.M.R. Hoen, T. Tan, J.C. Fransoo,

G.J. van Houtum

Martijn Mes, Matthieu van der Heijden, Peter Schuur

Marco Slikker, Peter Borm, René van den Brink

A.L. Kok, E.W. Hans, J.M.J. Schutten W.H.M. Zijm

R.J.I. Basten, M.C. van der Heijden, J.M.J. Schutten 
Ocean Container Transport: An Underestimated

3032010 and Critical Link in Global Supply Chain Performance

3022010 Capacity reservation and utilization for a manufacturer with uncertain capacity and demand

3002009 Spare parts inventory pooling games

2992009 Capacity flexibility allocation in an outsourced supply chain with reservation

2982010 An optimal approach for the joint problem of level of repair analysis and spare parts stocking

Responding to the Lehman Wave: Sales

2972009 Forecasting and Supply Management during the Credit Crisis $2962009 \frac{\text { An exact approach for relating recovering surgical }}{\text { patient workload to the master surgical schedule }}$

An iterative method for the simultaneous

2952009 optimization of repair decisions and spare parts stocks

2942009 Fujaba hits the Wall(-e)

2932009 Implementation of a Healthcare Process in Four Different Workflow Systems

2922009 Business Process Model Repositories - Framework Zhiqiang Yan, Remco Dijkman, Paul and Survey

2912009 Efficient Optimization of the Dual-Index Policy Using Markov Chains

$2902009 \frac{\text { Hierarchical Knowledge-Gradient for Sequential }}{\text { Samping }}$ Sampling

Analyzing combined vehicle routing and break

2892009 scheduling from a distributed decision making perspective

2882009 Anticipation of lead time performance in Supply Chain Operations Planning $2872009 \frac{\text { Inventory Models with Lateral Transshipments: A }}{\text { Review }}$ 2862009 Efficiency evaluation for pooling resources in

2852009 A Survey of Health Care Models that Encompass Multiple Departments

$2842009 \frac{\text { Supporting Process Control in Business }}{\text { Collaborations }}$

2832009 Inventory Control with Partial Batch Ordering
Jan C. Fransoo, Chung-Yee Lee

Y. Boulaksil; J.C. Fransoo; T. Tan

F.J.P. Karsten; M. Slikker; G.J. van Houtum

Y. Boulaksil, M. Grunow, J.C. Fransoo

R.J.I. Basten, M.C. van der Heijden, J.M.J. Schutten

Robert Peels, Maximiliano Udenio, Jan C. Fransoo, Marcel Wolfs, Tom Hendrikx

Peter T. Vanberkel, Richard J.

Boucherie, Erwin W. Hans, Johann L. Hurink, Wineke A.M. van Lent, Wim H.

R.J.I. Basten, M.C. van der Heijden, J.M.J. Schutten

Pieter van Gorp, Ruben Jubeh, Bernhard Grusie, Anne Keller

R.S. Mans, W.M.P. van der Aalst, N.C. Russell, P.J.M. Bakker Grefen

Joachim Arts, Marcel van Vuuren, Gudrun Kiesmuller

Martijn R.K. Mes; Warren B. Powell; Peter I. Frazier

C.M. Meyer; A.L. Kok; H. Kopfer; J.M.J. Schutten

Michiel Jansen; Ton G. de Kok; Jan C. Fransoo

Colin Paterson; Gudrun Kiesmuller; Ruud Teunter; Kevin Glazebrook

P.T. Vanberkel; R.J. Boucherie; E.W. Hans; J.L. Hurink; N. Litvak

P.T. Vanberkel; R.J. Boucherie; E.W. Hans; J.L. Hurink; N. Litvak

S. Angelov; K. Vidyasankar; J. Vonk; P. Grefen

O. Alp; W.T. Huh; T. Tan van Harten 
2822009

Translating Safe Petri Nets to Statecharts in a

Structure-Preserving Way

2812009 The link between product data model and process model

2802009 Inventory planning for spare parts networks with delivery time requirements

2792009 Co-Evolution of Demand and Supply under Competition

Toward Meso-level Product-Market Network

2782010 Indices for Strategic Product Selection and

(Re)Design Guidelines over the Product Life-Cycle

An Efficient Method to Construct Minimal Protocol $2772009 \stackrel{\text { Adaptors }}{\text { Ad }}$

2762009 Coordinating Supply Chains: a Bilevel Programming Approach

2752009 Inventory redistribution for fashion products under demand parameter update

2742009 Comparing Markov chains: Combining aggregation and precedence relations applied to sets of states

2732009 Separate tools or tool kits: an exploratory study of engineers' preferences

An Exact Solution Procedure for Multi-Item Two-

2722009 Echelon Spare Parts Inventory Control Problem with Batch Ordering

2712009 Distributed Decision Making in Combined Vehicle Routing and Break Scheduling

Dynamic Programming Algorithm for the Vehicle

2702009 Routing Problem with Time Windows and EC Social Legislation

2692009 Similarity of Business Process Models: Metics and Evaluation

2672009 Vehicle routing under time-dependent travel times: the impact of congestion avoidance

2662009 Restricted dynamic programming: a flexible framework for solving realistic VRPs
R. Eshuis

J.J.C.L. Vogelaar; H.A. Reijers

I.C. Reijnen; T. Tan; G.J. van Houtum

B. Vermeulen; A.G. de Kok

B. Vermeulen, A.G. de Kok

R. Seguel, R. Eshuis, P. Grefen

Ton G. de Kok, Gabriella Muratore

G.P. Kiesmuller, S. Minner

A. Busic, I.M.H. Vliegen, A. SchellerWolf

I.M.H. Vliegen, P.A.M. Kleingeld, G.J. van Houtum

Engin Topan, Z. Pelin Bayindir, Tarkan Tan

C.M. Meyer, H. Kopfer, A.L. Kok, M. Schutten

A.L. Kok, C.M. Meyer, H. Kopfer, J.M.J. Schutten

Remco Dijkman, Marlon Dumas, Boudewijn van Dongen, Reina Kaarik, Jan Mendling

A.L. Kok, E.W. Hans, J.M.J. Schutten

J. Gromicho; J.J. van Hoorn; A.L. Kok; J.M.J. Schutten;

Working Papers published before 2009 see: http://beta.ieis.tue.nl 